\title{
Social Life Cycle Assessment Used in Indigenous Contexts: A Critical Analysis
}

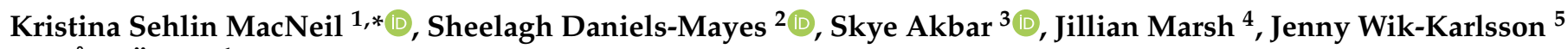 \\ and Åsa Össbo ${ }^{1}$ \\ 1 Várdduo-Centre for Sami Research, Umeå University, 90187 Umeå, Sweden; asa.ossbo@umu.se \\ 2 Indigenous Research Hub, Faculty of Arts and Social Sciences, The University of Sydney, \\ Camperdown, NSW 2050, Australia; sheelagh.daniels-mayes@sydney.edu.au \\ 3 UniSA Business, City West Campus, University of South Australia, Adelaide, SA 5000, Australia; \\ skye.akbar@unisa.edu.au \\ 4 Moondani Balluk Indigenous Academic Unit, Victoria University, Footscray, Melbourne, VIC 3011, Australia; \\ jillian.marsh@vu.edu.au \\ 5 Sámiid Riikkasearvi, 90621 Umeå, Sweden; jenny@sapmi.se \\ * Correspondence: kristina.sehlin-macneil@umu.se; Tel.: +46-(0)90-786-6297
}

check for updates

Citation: Sehlin MacNeil, K.; Daniels-Mayes, S.; Akbar, S.; Marsh, J.; Wik-Karlsson, J.; Össbo, Å. Social Life Cycle Assessment Used in Indigenous Contexts: A Critical Analysis. Sustainability 2021, 13, 5158. https://doi.org/10.3390/su13095158

Academic Editor: Danny Hunter

Received: 15 April 2021

Accepted: 28 April 2021

Published: 5 May 2021

Publisher's Note: MDPI stays neutral with regard to jurisdictional claims in published maps and institutional affiliations.

Copyright: (c) 2021 by the authors. Licensee MDPI, Basel, Switzerland. This article is an open access article distributed under the terms and conditions of the Creative Commons Attribution (CC BY) license (https:// creativecommons.org/licenses/by/ $4.0 /)$.

\begin{abstract}
This paper evaluates the method Social Life Cycle Assessment (S-LCA) from the perspectives of Indigenous methodologies and Indigenous standpoint, in order to identify some strengths and limitations of using S-LCA in Indigenous contexts. Life Cycle Assessment (LCA) is used to measure environmental impacts connected with all stages of the life cycle of a commercial product, process, or service. S-LCA is a methodology designed to include the social aspects of sustainability in the LCA methodology. S-LCA emphasizes stakeholder involvement and the United Nations Environment Programme (UNEP) S-LCA guidelines (2020) lists Indigenous communities as possible stakeholders. With a focus on Indigenous communities in the Arctic region we also include comparative aspects from Australia to generate new conceptualizations and understandings. The paper concludes that S-LCA has the potential to facilitate opposing worldviews and with some further developments can be a valuable methodology for Indigenous contexts.
\end{abstract}

Keywords: Arctic; Australia; Indigenous methodologies; Indigenous peoples; Indigenous standpoint; Sámi; social life cycle assessment; S-LCA

\section{Introduction}

This paper critically analyzes existing guidelines for Social Life Cycle Assessment [1] against a background of scholarly literature on Indigenous methodologies and Indigenous standpoint, in order to evaluate the potential benefits and/or challenges of the method when used specifically in Indigenous contexts. This paper is to be viewed as a contribution to the theoretical understanding of the methodology Social Life Cycle Assessment. We provide a new angle by viewing the guidelines from a different vantage point, through an Indigenous methodologies and standpoint lens. The authors are Indigenous and non-Indigenous, scholars or practitioners, with expertise in various aspects of Indigenous histories, societies, and cultures. The method of S-LCA is extensively described in guidelines provided by the United Nations Environmental Programme [1]. Indigenous methodologies and Indigenous standpoint, highlighted in this paper, are well-established research theories and methods accessible through the global canon on those topics (see for example seminal works by Denzin et al.; Nakata; Smith; Kovach; Porsanger; Kuokkanen; Wilson; Moreton-Robinson; Watson) [2-10].

Indigenous peoples, as described by the United Nations [11], are estimated to number more than 370 million people spread across 70 countries worldwide and practicing unique traditions, they retain social, cultural, economic, and political characteristics that are distinct 
from those of the dominant societies in which they live. On a global scale Indigenous peoples' lands and waters are subjected to high levels of extractive industry activity and extractivism often has negative impacts on the lives and livelihoods of Indigenous communities. Protecting and preserving the natural world is most often placed second to extracting resources for financial gain in the global capitalist market economy system, placing Indigenous communities at risk of being subjected to different forms of violent societal structures, including extractive violence [12]. Even in an era of pushing for green energy transformation, possibly viewed and marketed as less "dirty" and invasive, these efforts often still impact Indigenous communities in deleterious ways. One example being the recent push for placing wind farms in Northern Sweden, in the Swedish part of Sápmi, the Sámi homeland, thus placing the windmills on Sámi reindeer grazing lands. Here, research has shown that the reindeer actively avoid areas in and around these wind farms and consequentially the conditions for reindeer grazing is even further impaired [13]. The issue of consistently shrinking reindeer grazing lands due to various kinds of extractivism and the resulting devastating impact on the availability of lichen that the reindeer feed on, is also further aggravated by climate change [14].

Many Indigenous peoples' worldviews center on holistic people-planet relationships where relationality and reciprocity guides how people care for land and how the land cares for the people in return. These relationships are based on complex knowledge systems where understanding the land is a product of multiple generations' learning and sharing knowledge over centuries [15,16]. According to Swan and Raphael's 'guiding principles' to good mental health, for Indigenous peoples, "land is central to well-being" [17] (p. 14). Likewise, Australian Aboriginal scholar Vicki Grieves' research on Social and Emotional Well-being (SEWB) in Aboriginal communities concluded that "the connectedness that exists in Aboriginal society - to family, kin, the natural world and the universe-is to be found in Spirituality, the blueprint for culture." [18] (p. 48). In other words, connection to land and environment, to place and Country, is just as significant for good health (physical and mental, social, and emotional well-being) as the absence of disease. Within these longstanding frameworks of sense making, of understanding, of knowledge, it is not possible to separate people from land and land from people. Similarly, studies $[19,20]$ exploring the cultural meanings of suicide among Sámi in Sweden found that this was connected to the difficulties of maintaining Sámi identities and that threats to Sámi identities included "... exploitation of Sámi lands (by forestry, tourism, mining activities, wind and hydro power plants and societal infrastructure) ... " [19] (p. 3). Studies related to Sámi health show the complexities and connections that exist within Sámi identities, health and connections to land and indicate that for reindeer herding Sámi there is a constant struggle tied to power inequalities, loss of culture, language and livelihoods, embedded in the loss of land [16] (p. 141). Critical to well-being is the concept of inclusivity [21]. However, whenever the word inclusivity is mentioned, the first question that comes to mind is who is including whom? Who is the main actor? Where does the power lie? Who is the primary initiator of the process of inclusiveness? Because of a legacy of " ... violation and abuse of power, loss of land, language, livelihood, children, religion and traditions." [16] (p. 141), Indigenous communities are rarely the ones in power to initiate the process of inclusion.

With this in mind, we see some potential problems with using S-LCA as a method in Indigenous contexts. S-LCA, while offering some flexibility to how the method is used, still suggests separating the social, or human, world from the natural world, the land, and waters. Epistemological and ontological tensions created through cultural biases potentially obstructs a global philosophical standpoint of the full range of relationships between people and country prompting a critical investigation that fully discloses and discards exclusive claims to knowledge of the basis of modern Western science and its philosophical understandings [22]. For example, Indigenous Australian understandings of such relationships are deeply personal and intimately woven into a living archive commonly referred to as songlines [23,24]. Writing of the Australian Indigenous context, Moreton-Robinson describes Aboriginal peoples' relationships with land as forming an 
'ontological belonging'; Aboriginal peoples' spiritual beliefs are based on systems that tie one into the land, to other members of the group [25]. Moreton-Robinson continues: "Our ontological relationship with the country means that there is an incommensurable difference between sense of self, home and belonging to place. Our ontological relationship to land, the ways that country is constitutive of us, and therefore the inalienable nature of our relation to land, marks a radical, indeed incommensurable, difference between us and the non-Indigenous" [25] (p. 31). Similarly, Sámi scholar Rauna Kuokkanen writes about the logic of the gift, how according to many Indigenous worldviews the gift of the land entails responsibility and reciprocity: "The gift reflects a worldview that emphasizes establishing and sustaining relationships with the land rather than taking it for granted. When there is no land to have a relationship with-that is, when land is expropriated or used for other more "profitable" purposes, be it in the name of civilization or in the interests of the globalized economy-the gift is made impossible and so is the survival of the people." [7] (p. 161).

Many Indigenous peoples' relationships with the environment and its resources were designed to ensure survival not just of those in the present but for those generations yet to come. "It was sustainable because, individually and collectively, Aboriginal peoples had come to accept a responsibility for the conservation of natural resources and to accept the discipline associated with that responsibility" [26] (p. 8). Therefore, the concept of 'life cycle' provided in the S-LCA approach differs from many Indigenous peoples' knowledge frameworks. One example is the intergenerational impact of hydropower expansion in a Sámi local community, where it was found that the impacts span several generations and thus that the actual use phase was almost impossible to estimate [27]. The S-LCA Guidelines offer a definition of life cycle perspective as "from extraction of raw material to end of life" with a focus on products [1] (p. 16). While this does not stipulate a particular time frame there is no discussion of potential impacts on generations to come.

Nonetheless, we see potential benefits speaking for the use of S-LCA in Indigenous contexts. The methodology is presented as being flexible so there seems to be possibility to adapt the methods to better suit both Indigenous and mainstream worldviews. S-LCA appears to be a method with a strong focus on ethics of care, an effort to do right by people. However, Indigenous ethics of care differ to mainstream Western perspectives, as the efforts to do right by people cannot be separated from the efforts to do right by the land [28].

\section{Materials and Methods}

The materials used for this critical examination of S-LCA are scientific literature and the UNEP guidelines on S-LCA as well as scientific literature on Indigenous methodologies and Indigenous standpoint.

\subsection{Social Life Cycle Assessment}

Social Life Cycle Assessment (S-LCA) is a methodology derivative of the already established Environmental Life Cycle Assessment method. The essence of S-LCA is to assess the social and sociological aspects of products, organizations or services to investigate their impacts along the life cycle discussed above. For example, S-LCA can be used to investigate social impacts associated with the extraction and processing of raw materials, manufacturing, distribution, use, reuse, maintenance, recycling and final disposal. The method can involve quantitative, semi-quantitative or qualitative data collection-or a mix between these- and uses generic and site-specific data. S-LCA can be applied on its own or can also be used as a complement to Environmental Life Cycle Assessments and other similar techniques [1].

We base the core of our evaluation of S-LCA on the UNEP S-LCA Guidelines from 2020 [1]. However, to further understand S-LCA we have reviewed several scientific articles [29-35]. These articles were first found through topic searches (including title, abstract, author keywords and keywords plus) on Web of Science using the keywords: "social life cycle assessment" AND wind; "social life cycle assessment" AND indigenous; 
and "social life cycle assessment" AND culture; S-LCA AND wind; S-LCA AND culture; S-LCA AND indigenous. The keywords were chosen because of the focus of this evaluation, social life cycle assessment when used on Indigenous peoples' lands, considerations for Indigenous cultures and examples of social life cycle assessments of wind parks. The searches yielded a total of seven articles, three for S-LCA and culture; one for S-LCA and Indigenous; and three for S-LCA and wind. Two of the articles in the search category S-LCA and culture was the same as one in the S-LCA and Indigenous category, and one of the articles on S-LCA and culture was in fact on culturing algae, making a total of six relevant articles. The time span searched was between 2009 to 2021. The timespan was chosen as the first UNEP S-LCA guidelines were published in 2009. The meager search result is not an indicator of S-LCA being under researched. A topic search on Web of Science only using the keywords "social life cycle assessment", during the same time span, yielded 299 articles. This indicates that there is less research on S-LCA specifically focusing on particular areas such as Indigenous peoples, culture, or wind power. Following relevant references found through the seven articles, an additional four articles were accessed [36-39].

\subsection{Indigenous Methodologies and Indigenous Standpoint}

Indigenous peoples have been and are still often objects of research-objects of curiosity-rather than subjects performing research on their own issues [4-7,40]. One response to this is the field of Indigenous methodologies that has emerged in the last 30 years and taken root within the mainstream academe, with a large number of prominent Indigenous scholars contributing to the field [2]. Development of Indigenous approaches to research continues and in recent years Indigenous voices have become increasingly evident in academic publishing [41,42]. However, Indigenous methodologies should not be viewed as new - rather they are as old as the cultures that developed and practice/d them, pursuing knowledge production for generations. Indigenous methodologies are not one specific theory, method, and way of performing research, on the contrary they are as varied as the many peoples that use them [43]. Karen Sinclair, Ngarrindjeri scholar from Australia, describe Indigenous methodologies as "offering 'possibilities' and 'opportunities' for ways of thinking and knowing which are grounded in my own Indigenous epistemology" [43] (p. 64). Another Indigenous scholar, Shawn Wilson from Canada, poses that rather than talking about "an Indigenous perspective on research", implying that mainstream Western research paradigms (e.g., positivist, post-positivist, critical and constructivist) are the norm and Indigenous research are only different perspectives on these we should talk about an Indigenous research paradigm, positioned alongside the Eurocentric dominant research paradigms [44] (p. 176). What differs the Indigenous paradigm from the dominant research paradigms is that it rejects the idea that knowledge is individual. Wilson highlights that knowledge produced through research cannot be owned, it is "a relationship with all of creation. It is with the cosmos, it is with the animals, with the plants, with the earth that we share this knowledge." [44] (p. 176). Underpinning this epistemological thesis is worldview, something reiterated by other Indigenous scholars such as Russell Means and Bayard Johnson who write about connectedness in a Native American context and how an individual is never alone but always part of the entire Universe, thus people are responsible for and accountable to Earth and all aspects of it [45]. Similarly, Sámi scholar Rauna Kuokkanen, states that remaining connected and maintaining balance with Earth on all levels was (and is still) fundamental to many Sámi people as this could ensure survival in sometimes treacherous climates and landscapes [7] (p. 34). The importance of including worldviews in social life cycle assessments is mentioned in two of the articles on S-LCA found through the search on Web of Science. Both by Pizzirani et al., who advocate for inclusion of worldviews and culture in their papers exploring the potential place for culture in life cycle assessments [32,33].

Despite the multiplicity of Indigenous methodologies, most scholars agree that there are some central shared principles that influence them $[5,6,40,44,46-48]$. One example is shared by Renee Pualani Louis who proposes that the literature on Indigenous method- 
ologies presents "four unwavering principles: relational accountability; respectful representation; reciprocal appropriation; and rights and regulation." [47] (p. 133). Where rights and regulation stipulate that research with Indigenous peoples, guided by Indigenous protocols, should be conducted as collaborations and that no research results should be published without the consent of the research participants. It also refers to ownership of intellectual property and the control over publication and reporting of shared knowledge. This is one of many areas where Indigenous methodologies intersect with protocols and procedures of human research ethics [49].

As a complement to these four principles can be added three R's: Respect, Reciprocity, and Relationships [50]. The R's should guide the way that researchers and research participants conduct themselves in a research process. There are several versions of the $\mathrm{R}^{\prime}$ s, for example, in Archibald's methodological framework, storywork, the four Rs of respect, responsibility, reverence, and reciprocity relate to ways of working with people and with Indigenous knowledges [51]. The remaining principles of holism, interrelatedness, and synergy refer to how Indigenous knowledges and Indigenous stories are used in research processes [51]. As stated, and practiced by Sehlin MacNeil, relationships are valued and protected by respecting each other and the intellectual property shared which should also be reciprocal, research should not be extractive but mutually beneficial for both researcher and research participants [12] (pp. 19-31). When research is conducted on rather than with Indigenous peoples, thus without adherence to Indigenous protocols ethics and methodologies, the results are rarely fully relevant to the Indigenous communities they impact [12,49].

Indigenous standpoints flow from Indigenous ontologies, an example from Australia is 'Yura Muda' or ancient human connections including spiritual, economic, and deeply personal kin ties between people and country [52]. These connections form the basis from which Indigenous peoples are empowered and free from colonialism, or continuously re-traumatized by the destruction of places of cultural significance, often due to commercial interests that are far removed from Indigenous interests. In analyzing the interface between Indigenous peoples and mining companies in Australia, Marsh found that there were inherent weaknesses with regards to treatment of Indigenous peoples in regulation processes around mining: "questions remain as to how to better respond to the ongoing absence of recognition of Indigenous rights, ancient traditions and practices, sovereignty, and continuity with land and spirit." [52] (p. 175). One alternative could be to embrace Indigenous narratives in ways that would build mutually respectful relationships; however colonial praxis deeply embedded within legislation and policy often create a default setting that trigger each other and effectively exclude Indigenous ontologies.

In recent decades, environmentalists and environmental thinkers have begun to shift away from the belief that human is the starting point for all moral action. Instead, animals and nature have begun to emerge in theories or movements such as Land ethic, Gaiahypothesis and Deep Ecology. Significantly, Leopold contends that all ethics is based on the single premise that an individual is a member of a community of interdependent parts and land ethic is expanding the community to include "soils, water, plants, and animals, or collectively, the land" [53] (p. 219). These are ideas that converge with certain parts of the worldview of many Indigenous peoples. The power structure of humans as conquerors of land is changed to "plain members" and citizens of the land-community, respecting its fellow members as well as the community. Problematically, the convergence between land ethics and Indigenous peoples' ethics has been critiqued in lacking important elements, and reproducing settler narrative and the silencing of Indigenous knowledges [54]. While the Leopoldian land ethic, further developed by Callicott [55], unfolds as monistic promoting one single ethic framework to be applied universally, Hester et al. suggest that Indigenous worldviews are pluralistic and based on respect for all beings as a primary that shapes epistemology, not as a method for understanding "how the world really is", but as "a mode of engagement in the world" [56] (p. 281). 


\section{S-LCA in a Sámi Context (Results)}

To assess how the method Social Life Cycle Assessment could be used to elucidate social impacts in Indigenous contexts we construct a hypothetical case. A Social Life Cycle Assessment is commonly undertaken in four phases [1] (p. 21):

1. Goal and scope are decided, what is the purpose of the study and the breadth and depth?

2. A social life cycle inventory is conducted, including some or all of the following depending on which type of S-LCA is being conducted: Identifying what data to collect; Collecting data for selected and/or relevant stakeholders and subcategories as well as complementary data for impact assessment (if needed); Collecting site-specific and generic data for activity variables and unit processes; and Collecting data for weighting and scoring.

3. A social life cycle impact assessment is made, this involves understanding and evaluating the potential social impacts of the product, organization or service being assessed. It can be analyzing social impacts that have occurred, are occurring or will occur in the future. The focus is on potential social impacts understood as: "the likely presence of a social impact, resulting from the activities/behaviors of organizations linked to the life cycle of the product or service and from the use of the product itself." [1] (p. 80).

4. Interpretation of data, this includes a full review of all data collected and the formulation of conclusions and recommendations.

This is an iterative process, and the interpretation of data (last phase) can lead back to the first phase, goal and scope, if the data collected shows that the assessment process needs to be altered.

The S-LCA method calls for stakeholder inclusion. In the UNEP 2020 Guidelines, 'respect for Indigenous communities' is listed as a subcategory within the stakeholder category 'Local community'. 'Indigenous rights' is also listed as a target within goal 10 of the 17 Sustainable Development Goals (SDGs) that have been internationally accepted by governments, organizations and industries [57].

The importance of stakeholder inclusion should be apparent through all phases of an S-LCA; however, consultation with stakeholders seems to happen mainly in phase 2 , the inventory phase, when data collection is conducted. In the first phase, goal and scope, the social topic/s of interest are to be defined and subsequently the stakeholders and subcategories and/or impact categories are to be selected. The UNEP guidelines advocates for participatory approaches in stakeholder selection that is, to let actors involved in the product/organization or service to be assessed, to be active in the design of the study. This can contribute to a higher local relevance and "can help in the selection of a final set of indicators that reflect stakeholders' values, improves democratic representation, and promotes empowerment and learning opportunities for communities while encouraging partnerships." [1] (p. 51). The emphasis on stakeholder inclusion is also designed to increase the legitimacy of assessments.

To understand how S-LCA as a method could work from an Indigenous standpoint, we use a hypothetical (however, not actually unfamiliar or uncommon) case, and apply S-LCA to evaluate the social impacts on a Sámi reindeer herding community (stakeholders) of a wind power park placed on said Sámi reindeer herding community's reindeer grazing land. The geographical location is northern Sweden/Sápmi. Firstly, from the Sámi reindeer community standpoint, what information would need to be disclosed in order to understand social impacts?

It is roughly estimated that there are between 20-40,000 Sámi people in Sweden; however these figures are not conclusive as Sweden does not employ any kind of census with regard to ethnicity [58]. Approximately 4600 Sámi in Sweden own reindeer, but it is difficult to estimate how many are involved in a Sámi reindeer herding [58]. In Sweden, Sámi property and customary rights are tied to the reindeer. There are 51 reindeer herding Sámi communities, they are each allocated specific reindeer grazing areas, and there is a 
set number of reindeer allowed to each community according to calculations regarding the capacity of specific geographical areas and how many animals areas can hold and this is all governed by Swedish law [59]. For reindeer herding Sámi, the reindeer not only represents the ability to access and use traditional lands but also sustains language, as Sámi language is widely used among the herders, as well as culture, all parts of the animal are used for food or Duodji Sámi craft $[60,61]$. The reindeer is central also in Sámi creation stories and ancient as well as contemporary expressions of art [62]. Thus, it is necessary to understand reindeer and the relationship between Sámi reindeer herders, their animals, and their lands to understand social impacts in our hypothetical case.

Reindeer in Sweden are semi-domesticated, migratory animals, they move with the seasons and follow specific routes, the Sámi reindeer herders follow their animals. Reindeer are very sensitive animals, when disturbed they can shy away from an area even if it is a good place for grazing [13]. In our hypothetical case the proposed wind park is placed on prime reindeer grazing land and a migratory route for the animals, the area is necessary for reindeer belonging to this particular community to graze on in the winter. The wind park includes 40 windmills as well as several service roads to access these. The total area affected also includes the forest that needs to be felled in order to build the park, clear-cutting forest means destroying the grazing for the reindeer, as the ecosystem is disturbed with consequential loss of lichen. Reindeer graze on particular types of lichen, which grows on the ground and on trees [14].

In phase one of our hypothetical S-LCA the goal and scope is defined as: Focus on product, i.e., the wind farm; goal is to assess and compare the potential social impacts of the wind farm; scope is to assess the potential social impacts of the wind farm-from the building stage to the end of life stage-on the reindeer herding Sámi community, which is also selected as the stakeholders for the study.

In phase two, the inventory phase, data is collected. For this study already published quantitative scientific data on reindeer movement affected by the presence of windmills is collected. Qualitative data in the form of interviews with the reindeer herding Sámi community is also collected, a focus group interview method is used.

The interview data collected yields the following results as information shared by the Sámi reindeer herders:

- The reindeer shy away from windmills even if they stand on prime grazing land.

- Placing this wind farm in this location will severely shrink this community's access to reindeer grazing in the winter.

- This will impede traditional reindeer husbandry and might force the community to support feed (as the reindeer cannot access any lichen, they must be fed pellets or hay) their animals, this is costly and time consuming as well as bad for the reindeers' health.

- In the long run this might force the community to give up reindeer herding.

- This will affect their connections to their lands and how they can retain the language and the culture.

- It will also affect knowledge transfer, if the land cannot be used, the stories connected to it will be silenced. Thus, many young people will not be able to access knowledge about the area, the knowledge about how the land was once used will disappear.

- The community says that this can create negative health and well-being issues.

In phase three, the social impact assessment is made, and the sets of data are reviewed and discussed. In phase four, the interpretation of data phase, the data is further analyzed, and conclusions made. Recommendations are written up based on the data collected. In this case, the data shows that placing a wind farm in this particular location will potentially have severe consequences for the affected reindeer herding Sámi community. A worst case scenario indicates that they will be forced to give up their traditional livelihood and that this can affect language, culture and connection to land. A further consequence can be health and well-being issues. 
Our hypothetical case is a likely one and previous research points to these scenarios actually happening. Various kinds of impact assessments are also made in conjunction with new construction or extractive industry activities on Sámi reindeer grazing lands [63]. What then could an S-LCA bring to the table that these other types of assessments would not? How could, in this case, a Social Life Cycle Assessment benefit both stakeholders and energy production company (wind farm owner) in a way that would make it a more successful and preferable assessment model?

\section{S-LCA and Indigenous Peoples (Discussion)}

There are some obvious limitations with the S-LCA methodology presented in the articles reviewed, and also generously pointed out by UNEP in their own guidelines. Pizzirani et al. state that "Cultural indicators, in particular, although present in SLCA subcategories, are limited and are generally underrepresented in S-LCA studies" [33] (p. 664). Research on S-LCA point to limitations such as "the inherent value-laden and context specific nature of social aspects was and remains one of the key challenges for developing a general applicable model." [37] (p. 435). The fact that social matters can be messy and not easily fit into neat columns and mathematical formulas is by some presented as a problem. While van Haaster et al. recognize that all things cannot be measured quantitatively, they also indicate that qualitative methods would be less valuable: "A potential problem with the qualitative indicators is that their evaluation is subjective in nature." [37] (p. 435). This sort of rhetoric pits qualitative and quantitative methods against each other when they should be viewed as complementary. If the methods used to collect data from stakeholders is deemed less valuable than the data collected through mathematical quantification, then stakeholders' risk not being included on equal terms in a Social Life Cycle Assessment.

Di Noi et al. present limitations in terms of lack of available social data in data bases such as the 'Social Hotspot Database' from for example conflict zones, when the entire life cycle of a product is to be measured [38]. Their concern is that an S-LCA might not yield the correct recommendations if data is inconclusive, and they suggest further developments of the methodology.

In several of the articles reviewed, predominantly those on S-LCA and wind power, the focus is on financial aspects, here the stakeholder perspectives are hardly mentioned. For example, Noori et al. write that: "On the other hand, construction and transportation phases are responsible for most of the social impacts in all wind turbines. Construction phase leads in income and employment, causing more than 55\% of impacts. For the government tax indicator, transportation phase has the largest amount of impact by causing more than $40 \%$ of the impacts in all of the wind turbines. Moreover, use phase has the lowest contribution in the socio-economic phase as it uses a very low portion of resources during the lifetime of the wind turbine." [39] (p. 637). This seems to be quite typical in life cycle thinking, i.e., social impacts are seen as employment benefits to communities. On the contrary, as seen in our hypothetical case above, social impacts to some stakeholders can be detrimental to livelihoods, even if they would be presented with possible job opportunities. Thus, if social impacts are not measured from a capitalist standpoint, but rather from an Indigenous standpoint they may present very differently. Indigenous communities are often expected to participate and compete in market-based economies in order to have their basic needs satisfied to have food, protection and security. These fundamental needs should be understood as basic human rights and are not negotiable. Western markets and economies, with their set regulations and processes, also routinely overlook that many Indigenous peoples are, because of colonization, left with lands that are non-urban which can increase challenges of achieving successful and sustainable enterprises because of facing issues such as extreme weather, substandard infrastructure, distance from policy makers and distance from markets. This in addition to Indigenous specific business issues such as expectations of commercialization of culture for business participation [64]. 
Yet, there are also some important benefits of S-LCA. The heavy focus on stakeholder inclusion in order to make assessments locally relevant and legitimate is important and when it comes to assessments of products in Indigenous contexts this potentially places S-LCA in a league of its own. While the right to have one's voice heard on equal terms is often promised in situations like our hypothetical case, it is rarely realized when economic profit is prioritized over Indigenous connections to land [12,52]. S-LCA is simply an assessment tool to provide information about potential social impacts and as such it does promise to include stakeholder voices, however, it does not promise to create change or steer decision making processes. Is it possible that values, central to Indigenous communities, can be elucidated and better understood and respected if included in a rigorously modeled assessment such as an S-LCA? From an Indigenous methodology and Indigenous standpoint perspective, land is central because of the holistic relationships between human beings and the lands that they care for. Indigenous communities' knowledge systems and epistemologies are linked to their lands. Departing from a holistic worldview, it is not possible to separate environment and people [22-25].

The Social Life Cycle Assessment methodology indicates that it is possible to separate environment/planet, social/people and financial aspects/profit. This is called the threepillar approach [1: 16]. S-LCA is then described as being one of three methodologies, the one used to address the people pillar. In most Indigenous contexts the people-planet-profit pillars would not be so easily separated. In our hypothetical case, the Sámi reindeer herders and their animals are deeply interdependent with the environment, the planet, and profit for the community would be to be able to continue their traditional livelihood, connected to the land, their culture and language.

Nonetheless, with a commitment to real stakeholder involvement and depending on how seriously data collected from stakeholders is considered, as well as how respectfully the stakeholders' voices and opinions are treated, there is a potential for S-LCA to be of use for understanding situations experienced by Indigenous communities. In the least it should provide a platform for stakeholders to voice concerns. Best case scenario, going on our hypothetical case, it could provide an energy company with background information about social impacts and consequences that they were not aware of and this could in turn lead to a change of location for the wind farm that would benefit all parties involved. Fortier et al. provides an example of this where the renewable power company (ORPC) used stakeholder inclusive strategies when deciding a location for a tidal energy project. Their first action was to reach out to the local fishermen's association in order to assess whether their plans would disrupt the fishermen's work. This led to a change from the originally planned location. Other stakeholders involved in the process were local community members and members of the local Native American community. The energy company based their focus on stakeholder involvement on their belief in "agencies give permits, communities give permission." [36] (p. 215, quote quoted from Fortier et al.).

If, in our hypothetical case, the Sámi community was engaged in the S-LCA from the planning phase and if the assessment process was open to absorbing the Sámi community's shared information, historical perspectives, social and cultural values and understandings and worldviews, there would be an opportunity for an assessment to reflect a much broader, complex and accurate analysis of the situation. This should be as beneficial to the wind park owner as it would be for the Sámi reindeer herding community. Several potential conflicts, both present and future, could be transformed and/or avoided and new strategic collaborations could be established.

\section{Conclusions}

The S-LCA guidelines, while thoroughly described, are very complex and suggest that strands of existence can be separated, something that does not necessarily correlate with many Indigenous peoples' worldviews, where people-planet-cosmos relationships involve a holistic approach and people, land and cosmos exist in interdependence. Furthermore, there are already several aspects, directly or indirectly related to the colonization of 
Indigenous peoples' lands and consequential extractivism that impact Indigenous peoples in negative ways: extractive industry activities; tourism; military presence or operations; urbanization; racism and colonial attitudes; and climate change, to mention only a few. Given this, it can be difficult to see how the various S-LCA indicators for the local community, which includes Indigenous peoples as stakeholders, can actually be measured using methods suggested in the S-LCA guidelines. In all its complexity it is possible that S-LCA as a method will work to simplify and deconstruct Indigenous peoples' knowledge systems and complex relationships with their lands. A scenario that must be examined before proclaiming the overall usefulness of S-LCA is whether the call for "social sustainability, social inclusion and leaving no one behind" [1] (p. 6) does in fact include Indigenous peoples on Indigenous peoples' terms or even on equal terms. Or does S-LCA run the risk of becoming a new type of assimilation where deficiency perspectives are left to dictate what kind of people-planet-cosmos relationships count? In articles on Social Life Cycle Assessment the word 'holistic' is used recurrently to describe the methodology. Holistic seems to mean very different things in non-Indigenous and Indigenous contexts. Or is it simply that, more often than not, when 'holistic' is used by non-Indigenous scholars or practitioners, Indigenous perspectives are excluded? Holistic meaning whole, complete, universal, might not stretch to include those who oppose extractivism or industrial advancement in favor of saving their societies, livelihoods, languages, and cultures.

This is not to say that Indigenous communities are not themselves involved in tourism operations or even extractive industry activities. Indigenous communities, like all other communities, need adequate livelihoods to ensure survival in their current situations. However, colonization of Indigenous peoples' lands has robbed Indigenous peoples of self-determination as well as the power to decide what happens to their lands. Departing from this vantage point, we suggest that S-LCA can be a methodology used to benefit all stakeholders if expanded to include Indigenous knowledge systems and expertise when relevant. Pizzirani et al. suggest that inclusion of culture and/or cultural values is necessary in order to gain a more holistic and comprehensive assessment when life cycle assessment methods are used [32]. They further suggest that S-LCA is one such opportunity where this might be possible and that there are potential benefits of including culture, cultural values, and worldviews throughout the process of assessment, from planning phase through to recommendations made. However, Pizzirani et al. note that there are challenges, one of which pertains to data collection: "A key challenge is the collection and representation of any qualitative (social or cultural) information which may not be suitable to represent in the format of a functional unit." [32] (p. 1324). In the literature reviewed for this article, there is a clear pattern, a distinction and hierarchy between quantitative data (e.g., economic data) and qualitative data (e.g., social and cultural) where quantitative data is seen as more reliable, easier to collect and simply superior to qualitative data which, according to Pizzirani et al., might even be too time consuming to collect.

This correlates with the violent structures that many Indigenous peoples are already subjected to, their cultures, values and worldviews might be too time consuming to even hear [12]. If those cultural values and worldviews were heard they would probably inform the listener about a wish to protect, not extract the land. An often unpopular standpoint when pitted against industrial development and economic growth. In wanting to protect lands and livelihoods and not wanting to reduce people-planet-cosmos relationships to "functional units" Indigenous peoples are often portrayed as backward or unreasonable and their ideologies are trivialized or ignored [12] (p. 37). For S-LCA to make a difference and bring something new to the already large quantity of assessments available, we suggest that when used in Indigenous contexts, Indigenous methodologies, ideologies, knowledge systems and standpoints are engaged on equal terms, throughout the assessment process. Among other things, this would include engaging Indigenous expertise to collaborate from goal and scope to writing results. It would mean making a conscious and official effort to reduce power asymmetries in relationships to enhance engagement and collaboration, not only to 'include' Indigenous peoples in the process, but to open up for Indigenous 
communities to be engaged in the assessment process, on equal terms. It would mean that non-Indigenous assessors be open to learning about Indigenous cultural values and worldviews and it would require mutual respect, learning and problem solving.

The argument that increasing nature protection can be achieved only at the expense of economic development is one that hinders the environmental movement worldwide [65]. It also excludes decolonial praxis through a hierarchical framework of human-superior leadership and exploitation. This form of leadership is a mechanism for oppression and can be nurtured and normalized within individuals from a young age [23] (p. 222). Professor of law, Roderic O'Gorman, who specializes in constitutional environmental law, poignantly argues that in contemporary times, "At a time of great focus on human rights and the importance of protecting them within constitutions, the benefits of protecting the environment in this same way must be clearly articulated in a manner with which the public can engage" [66] (p. 456). O'Gorman goes on to argue for four specific responses needed for bridging the divide and engaging both sides of the argument: capitalizing on crisis situations; ensuring that economic concerns are adequately addressed; leveraging the support of the public and politicians; and linking environmental protection to national values [66] (p. 435). We argue that the S-LCA framework has the potential to facilitate balancing environmental protection and economic development. However, when S-LCA is used in Indigenous contexts, this can only be done if Indigenous knowledges, protocols, and practices are recognized, understanding that Indigenous 'human' rights are not easily separated from rights of land or water.

Thus, we call for a further development of the Social Life Cycle Assessment guidelines in order to address and amend some of the aforementioned issues, for example the current asymmetrical power hierarchies and perspectives that places quantitative data as superior to qualitative data. We recognize that the balance between Indigenous land protection interests and extractivism for profit interests is a 'wicked problem'. The idea of wicked problems was first conceived by theorists Rittel and Webber in relation to policy and planning and refers to a problem that cannot be easily resolved, or might even be impossible to solve because of contradictory, incomplete or changing requirements that can even be difficult to identify [67]. Rittel and Webber suggest that wicked problems often need to be solved and resolved, meaning that it is important to persist in trying to find ways forward: "In such fields of ill-defined problems and hence ill-definable solutions, the set of feasible plans of action relies on realistic judgment, the capability to appraise "exotic" ideas and on the amount of trust and credibility between planner and clientele that will lead to the conclusion, "OK let's try that" [67] (p. 164). We suggest that S-LCA is a methodology that has the capability to consider and engage opposing worldviews and formulate ideas for constructive re-solutions. We recommend that the guidelines for S-LCA include an emphasis on respectful reciprocity in regard to sharing knowledge and knowledge systems. Finally, we want to emphasize the great difference between inclusion and engagement and suggest that Social Life Cycle Assessment as a method, when used in Indigenous contexts, does not merely include Indigenous communities but rather encourages Indigenous communities to be engaged, on equal terms, throughout the assessment process.

Author Contributions: K.S.M. conceived the idea for this paper. K.S.M. and S.D.-M. structured, prepared materials and conducted analysis. K.S.M., S.D.-M., S.A., J.M., J.W.-K., Å.Ö. contributed expertise and literature/data to methodology, discussion and conclusions. K.S.M. wrote the paper. All authors have read and agreed to the published version of the manuscript.

Funding: This research was partly funded by the Swedish Energy Agency, through the project Damage Done, grant number 2018-002606. Kristina Sehlin MacNeil and Åsa Össbo are currently researchers within that project.

Institutional Review Board Statement: Not applicable.

Informed Consent Statement: Not applicable. 
Data Availability Statement: Not applicable.

Conflicts of Interest: The authors declare no conflict of interest.

\section{References}

1. UNEP. Guidelines for Social Life Cycle Assessment of Products and Organizations. 2020. Available online: https://www. lifecycleinitiative.org/library/guidelines-for-social-life-cycle-assessment-of-products-and-organisations-2020/ (accessed on 14 April 2021).

2. Denzin, N.K.; Lincoln, Y.S. Introduction. In Handbook of Critical and Indigenous Methodologies; Denzin, N.K., Lincoln, Y.S., Smith, L.T., Eds.; Sage: London, UK, 2008; pp. 1-20, ISBN 978-1-4129-1803-9.

3. Nakata, M.N. Disciplining the Savages, Savaging the Disciplines; Aboriginal Studies Press: Acton, ACT, Australia, 2007; ISBN 0855755482

4. Smith, L.T. Decolonising Methodologies: Research and Indigenous Peoples, 2nd ed.; Otago University Press: Dunedin, New Zealand, 2012; ISBN 978-1-877578-28-1pb.

5. Kovach, M. Indigenous Methodologies: Characteristics, Conversations, And Contexts; University of Toronto Press: Toronto, ON, Canada, 2010.

6. Porsanger, J. An essay about indigenous methodologies. In Special Issue on Northern Minorities; Nordlit, 15; Bäckström, P., Jernsletten, K., Theodorsen, C., Eds.; University of Tromsø, Faculty of Humanities: Tromsø, Norway, 2004.

7. Kuokkanen, R. Reshaping the University: Responsibility, Indigenous Epistemes, And the Logic of the Gift; UBC Press: Vancouver, BC, Canada, 2011.

8. Wilson, S. Research Is Ceremony: Indigenous Research Methods; Fernwood Publishing: Halifax, NS, Canada, 2008.

9. Moreton-Robinson, A. Towards an Australian Indigenous women's standpoint theory: A methodological tool. Aust. Fem. Stud. 2013, 28, 331-347. [CrossRef]

10. Watson, I. Re-centring First Nations knowledge and places in a terra nullius space. AlterNative 2014, 10, 508-520. [CrossRef]

11. UN Fact Sheet. Who are Indigenous Peoples? Available online: https://www.un.org/esa/socdev/unpfii/documents/5session_ factsheet1.pdf (accessed on 14 April 2021).

12. Sehlin MacNeil, K. Extractive Violence on Indigenous Country: Sami and Aboriginal Views on Conflicts and Power Relations with Extractive in-Dustries. Ph.D. Thesis, Umeå Universitet, Umeå, Sweden, 2017.

13. Skarin, A.; Sandström, P.; Alam, M. Out of sight of wind turbines-Reindeer response to wind farms in operation. Ecol. Evol. 2018, 8, 9906-9919. [CrossRef] [PubMed]

14. Horstkotte, T.; Lépy, É.; Risvoll, C. Working together: Reflections on a transdisciplinary effort of co-producing knowledge on supplementary feeding in reindeer husbandry across fennoscandia. In Nordic Perspectives on the Responsible Development of the Arctic: Pathways to Action; Springer Polar Sciences, Springer: Cham, Switzerland, 2021; pp. 293-317.

15. Howitt, R. Decolonizing people, place and country: Nurturing resilience across time and space. Sustainability $2020,12,5882$. [CrossRef]

16. Wilson, S.; Wilson, S.; Svalastog, A.L.; Gaski, H.; Senior, K.; Chenhall, R. Double perspective narrating time, life and health. AlterNative 2020, 16, 137-145. [CrossRef]

17. Swan, P.; Raphael, B. Ways Forward: National Aboriginal and Torres Strait Islander Mental Health Policy National Consultancy Report. 1995. Available online: http:/ /library.bsl.org.au/jspui/bitstream/123456789/353/1/Ways\%20forward_vol.1\%20\%26\%20 2\%20_1995.pdf (accessed on 14 April 2021).

18. Grieves, V. Aboriginal Spirituality: Aboriginal Philosophy the Basis of Aboriginal Social and Emotional Wellbeing. Cooperative Research Centre for Aboriginal Health, Discussion Paper Series: No. 9, 2009, Darwin. Available online: https: //www.pathwaysmh.com.au/Aboriginal_Philosophy.pdf (accessed on 14 April 2021).

19. Stoor, J.P.A.; Kaiser, N.; Jacobsson, L.; Renberg, E.S.; Silviken, A. “We are like lemmings": Making sense of the cultural meaning (s) of suicide among the indigenous Sami in Sweden. Int. J. Circumpolar Health 2015, 74, 27669. [CrossRef]

20. Stoor, J.P.A. Suicide among Sámi-Cultural Meanings of Suicide and Interventions for Suicide Prevention in Nordic Parts of Sápmi. Ph.D. Thesis, UiT the Arctic University of Norway, Tromsø, Norway, 2020.

21. Azmat, F. Social exclusion and social inclusion. In No Poverty. Encyclopedia of the UN Sustainable Development Goals; Leal Filho, W., Azul, A., Brandli, L., Lange Salvia, A., Özuyar, P., Wall, T., Eds.; Springer: Cham, Switzerland, 2020. [CrossRef]

22. Roothaan, A. Indigenous, Modern and Postcolonial Relations to Nature: Negotiating the Environment; Routledge: London, UK; New York, NY, USA, 2019.

23. Gombay, N.; Palomino-Schalscha, M. Indigenous Places and Colonial Spaces: The Politics of Intertwined Relations; Routledge: London, UK, 2018.

24. Neale, M.; Kelly, L. Songlines: The Power and Promise; Thames \& Hudson: Port Melbourne, VIC, Australia, 2020.

25. Moreton-Robinson, A. I still call Australia home: Indigenous belonging and place in a white postcolonising society. In Uprootings/Regroundings: Questions of Home and Migration; Ahmed, S., Castaneda, C., Fortier, S., Sheller, M., Eds.; Berg Publishers: Oxford, UK, 2003; pp. 23-40.

26. McBride, G.F. Adelaide's Recipe for Life: Wisdom of the Kaurna; Hawke Institute, University of South Australia: Adelaide, SA, Australia, 2000. 
27. Össbo, Å. 'A constant reminder of what we had to forfeit': Swedish industrial colonialism and intergenerational effects on Sámi living conditions in the area of upper Stuor Julevädno. Int. J. Crit. Indig. Stud. 2021, 14, 17-32.

28. MacGill, B. Aboriginal Education Workers in South Australia: Towards Equality of Recognition of Indigenous Ethics of Care Practices. Ph.D. Thesis, Flinders University, School of Australian Studies, Adelaide, SA, Australia, 2008.

29. Tseng, Y.-C.; Lee, Y.-M.; Liao, S.-J. An integrated assessment framework of offshore wind power projects applying equator principles and social life cycle assessment. Sustainability 2017, 9, 1822. [CrossRef]

30. Schlör, H.; Venghaus, S.; Zapp, P.; Marx, J.; Schreiber, A.; Hake, J.F. The energy-mineral-society nexus-A social LCA model. Appl. Energy 2018, 228, 999-1008. [CrossRef]

31. Holger, S.; Petra, Z.; Josephine, M.; Andrea, S.; Sandra, V.; Jürgen-Friedrich, H. The social footprint of permanent magnet production based on rare earth elements-a social life cycle assessment scenario. Energy Procedia 2017, 142, 984-990. [CrossRef]

32. Pizzirani, S.; McLaren, S.J.; Seadon, J.K. Is there a place for culture in life cycle sustainability assessment? Int. J. Life Cycle Assess. 2014, 19, 1316-1330. [CrossRef]

33. Pizzirani, S.; McLaren, S.J.; Forster, M.E.; Pohatu, P.; Porou, T.T.W.; Warmenhoven, T.A. The distinctive recognition of culture within LCSA: Realising the quadruple bottom line. Int. J. Life Cycle Assess. 2018, 23, 663-682. [CrossRef]

34. Sadhukhan, J.; Gadkari, S.; Martinez-Hernandez, E.; Ng, K.S.; Shemfe, M.; Torres-Garcia, E.; Lynch, J. Novel macroalgae (seaweed) biorefinery systems for integrated chemical, protein, salt, nutrient and mineral extractions and environmental protection by green synthesis and life cycle sustainability assessments. Green Chem. 2019, 21, 2635-2655. [CrossRef]

35. Vavra, J.; Munzarova, S.; Bednarikova, M. Social impacts of chemical products on local communities and their measurement. In Psychology and Psychiatry, Sociology and Healthcare, Education, Book Series; International Multidisciplinary Scientific Conferences on Social Sciences and Arts: Albena, Bulgaria, 2014; Volume II, p. 823.

36. Fortier, M.-O.P.; Teron, L.; Reames, T.G.; Munardy, D.T.; Sullivan, B.M. Introduction to evaluating energy justice across the life cycle: A social life cycle assessment approach. Appl. Energy 2019, 236, 211-219. [CrossRef]

37. Van Haaster, B.; Ciroth, A.; Fontes, J.; Wood, R.; Ramirez, A. Development of a methodological framework for social life-cycle assessment of novel technologies. Int. J. Life Cycle Assess. 2017, 22, 423-440. [CrossRef]

38. Di Noi, C.; Ciroth, A.; Mancini, L.; Eynard, U.; Pennington, D.; Blengini, G.A. Can S-LCA methodology support responsible sourcing of raw materials in EU policy context? Int. J. Life Cycle Assess. 2019, 25, 332-349. [CrossRef]

39. Noori, M.; Kucukvar, M.; Tatari, O. Economic input-output based sustainability analysis of onshore and offshore wind energy systems. Int. J. Green Energy 2015, 12, 939-948. [CrossRef]

40. Martin, K.; Mirraboopa, B. Ways of knowing, being and doing: A theoretical framework and methods for indigenous and indigenist research. J. Aust. Stud. 2003, 27, 203-214. [CrossRef]

41. Akbar, S. Marketing Remote Aboriginal and Torres Strait Islander Tourism to Australians; Univeristy of South Australia: Adelaide, Australia, 2016.

42. Graham, M. Some thoughts about the philosophical underpinnings of Aboriginal worldviews. Worldviews: Glob. Relig. Cult. Ecol. 1999, 3, 105-118. [CrossRef]

43. Sinclair, K. Educators' Understandings and Perspectives of Aboriginal and Torres Strait Islander Cultural Competence: A Mixed Methods Study. Ph.D. Thesis, University of South Australia, Adelaide, SA, USA, 2017.

44. Wilson, S. What is an indigenous research methodology? Can. J. Nativ. Educ. 2001, 25, 175-179.

45. Means, R.; Johnson, B. If You've Forgotten the Names of the Clouds, You've Lost Your Way: An Introduction to American Indian Thought and Philosophy; BookBaby: Portland, OR, USA, 2012.

46. Evans, M.; Miller, A.; Hutchinson, P.J.; Dingwall, C. Decolonizing research practice: Indigenous methodologies, aboriginal methods, and knowledge/knowing. In The Oxford Handbook of Qualitative Research; Leavy, P., Ed.; Oxford University Press: Oxford, UK, 2014.

47. Louis, R.P. Can you hear us now? Voices from the margin: Using indigenous methodologies in geographic research. Geogr. Res. 2007, 45, 130-139. [CrossRef]

48. Moreton-Robinson, A.; Walter, M. Indigenous methodologies in social research. In Social Research Methods; Walter, M., Ed.; Oxford University Press: Melbourne, Australia, 2009; pp. 1-18.

49. Daniels-Mayes, S.; Sehlin MacNeil, K. Disrupting assimilationist research principles and practices in australia and sweden: Self-determination through the enactment of indigenous diplomacies. Whitehead J. Dipl. Int. Rel. 2019, 21, 36.

50. Reid, J.B.; Taylor, K. Indigenous mind: A framework for culturally safe indigenous health research and practice. Aborig. Isl. Health Work. J. 2011, 35, 4.

51. Archibald, J.-A. Indigenous Storywork. Educating the Heart, Mind, Body, and Spirit; University of British Columbia Press: Vancouver, BC, Canada, 2008.

52. Marsh, J.K. Decolonising the interface between Indigenous peoples and mining companies in Australia: Making space for cultural heritage sites. Asia Pac. Viewp. 2013, 54, 171-184. [CrossRef]

53. Leopold, A. A Sand County Almanac. With Other Essays on Conservation from Round River 1949; Oxford University Press: New York, NY, USA, 1966.

54. Whyte, K. How Similar are Indigenous North American and Leopoldian Environmental Ethics? 2015. Available online: http:/ / papers.ssrn.com/sol3/papers.cfm?abstract_id=2022038 (accessed on 14 April 2021). 
55. Callicott, J. Baird. Earth's Insights: A Multicultural Survey of Ecological Ethics from the Mediterranean Basin to the Australian Outback; University of California Press: Berkeley, CA, USA, 1994.

56. Hester, L.; McPherson, D.; Booth, A. Indigenous worlds and Callicott's land ethic. Environ. Eth. 2000, 22, 273-290. [CrossRef]

57. United Nations Dept of Economic and Social Affairs Sustainable Development. The 17 Goals. Available online: https://sdgs.un. org/goals (accessed on 14 April 2021).

58. Sámediggi Samerna i Sverige. Available online: https://www.sametinget.se/samer (accessed on 14 April 2021).

59. Allard, C.; Brännström, M. Girjas Reindeer herding community v. Sweden: Analysing the merits of the Girjas case. Arct. Rev. 2021, 12, 56-79. [CrossRef]

60. Sehlin MacNeil, K.; Inga, N. Extraktivt våld och urfolks koppling till mark. Kulturella Perspektiv-Svensk Etnologisk Tidskrift 2019, $28,42-51$.

61. Nordin-Jonsson, Å. Árbediethu. In Árbediehtu: Samiskt Kulturarv och Traditionell Kunskap; Nordin-Jonsson, Å., Ed.; Sametinget and Uppsala Centrum för Biologisk Mångfald: Uppsala, Sweden, 2010.

62. Gaski, H. Nils-Aslak Valkeapää: Indigenous voice and multimedia artist. AlterNative 2008, 4, 155-178. [CrossRef]

63. Lawrence, R.; Larsen, R.K. The politics of planning: Assessing the impacts of mining on Sami lands. Third World Q. 2017, 38, 1164-1180. [CrossRef]

64. Akbar, S.; Hallak, R. Identifying business practices promoting sustainability in aboriginal tourism enterprises in remote Australia. Sustainability 2019, 11, 4589. [CrossRef]

65. Fisher, A.C.; Peterson, F.M. The environment in economics: A survey. J. Econ. Lit. 1976, 14, 1-33.

66. O'Gorman, R. Environmental constitutionalism: A comparative study. TEL 2017, 6, 435. [CrossRef]

67. Rittel, H.W.; Webber, M.M. Dilemmas in a general theory of planning. Policy Sci. 1973, 4, 155-169. [CrossRef] 